\title{
Corrosion Study of AISI 304, AISI 321 and AISI 430 Stainless Steels in a Tar Sand Digester
}

\author{
L.E. Umoru, A.A. Afonja, and B. Ademodi* \\ Department of Materials Science and Engineering, \\ Obafemi Awolowo University, Ile-Ife. Nigeria \\ *Department of Chemical Engineering, \\ Obafemi Awolowo University, Ile-Ife. Nigeria
}

\begin{abstract}
This work has investigated the corrosion properties of three types of stainless steels in a tar sand digester environment with the aim of establishing their relative resistances in the environment. The corrosion experiments for the stainless steels were conducted by the non-electrochemical immersion technique with corrosion rates expressed in mils per year (mpy). The spectroscopy analysis of the Nigerian tar sand was done by the energy dispersive $x$-ray analysis. The surface study of the corroded stainless steels was accomplished via a scanning electron microscopy (SEM) to reveal the form of corrosion.
\end{abstract}

The results of the corrosion experiments show that all the stainless steels have a relatively low corrosion rates $(<5$ mpy). The SEM analyses of their corroded surfaces however revealed great tendency in them to exhibit crevice and pitting corrosions. On the basis of resistance to the two forms of corrosion the AISI 321 stainless steel exhibited the best resistance in the environment.

Key words: Stainless steel, corrosion, tar sand

\section{INTRODUCTION}

Corrosion is one of the most destructive agents and perhaps the greatest consumer of metals known to man. It is the product of the interaction between the metallic materials and their environment. Depending on the type of environment and a number of prevailing conditions, corrosion may be chemical or electrochemical. As for the electrochemical corrosion there is 
metal dissolution at the anode as a result of oxidation reaction: $\quad \mathrm{M} \rightarrow \mathrm{M}^{\mathrm{n}+}+\mathrm{ne}^{-}$and a number of possible reduction reactions at the cathode. Unlike the electrochemical corrosion reactions that are accompanied by appreciable flow of electrons, chemical corrosions are subject purely to the basic laws of chemical kinetics. Examples of these type of corrosion abounds in the corrosion of metals in non-electrolytes such as organic acids, organic alcohol solution carbon tetrachloride etc ( Koser, 1980).

Tar sand, is a naturally occurring hydrocarbon described as black mass of solid aggregate, composed mainly of mineral matter, connate water and heavy oil bitumen (Miller and Misra, 1982). The heavy oil contains various fractions-representing parts of a system of multipolymers, the chemical properties of which change systematically with increasing molecular weight. Bitumen contains up to $5 \%$ by weight of sulphur that is bound together as a variety of aliphatic and aromatic organo-sulphur compounds. It is the hydrolysis of these compounds that results in various gaseous productions among which are $\mathrm{H}_{2} \mathrm{~S}, \mathrm{CO}_{2}$, and $\mathrm{H}_{2}$ (Peter et al, 1984).

The aggressive nature of the compounds of sulphur in bitumen on one hand and that of connate water containing dissolved ions and which is present in the form of a film around the sand particles in tar sands are often responsible for the deterioration of materials of construction of tar sand digesters (Umoru, 2001). According to Collins (1975) the connate water due to their high dissolving power contains some alkali and alkali earth metals that dissolve in the water as it percolates into the rock.

The digestion of tar sand by the hot water process constitutes a multi-component environment that is capable of ensuring both chemical and electrochemical reactions. The organic components of the bituminous content may constitute the chemical corrosion while the gas produced during digestion and the dissolved alkali and alkali earth metals of the connate water may constitute the electrochemical corrosion.

Metals depending on their chemical nature and that of the environment exhibit different corrosion resistances. Stainless steel is a family of iron-based alloys containing at least $11 \% \mathrm{Cr}$ and other elements such as $\mathrm{C}, \mathrm{Mn}, \mathrm{Si}, \mathrm{Ni}, \mathrm{Mo}, \mathrm{Ti}$, and $\mathrm{N}$. The high degree of chromium activity is actually the principal basis for utilizing it as an alloying element in corrosion resisting alloys. There are many types of stainless steels in the literature and these are often classified on the basis of their matrices as ferritic, martensitic and austenitic stainless steels. Not all the stainless steels are equally resistant in most environments but some have been developed through alloy additions to resist the aggression from anions in certain environment. Among these are the AISI430 ferritic grade, AISI304 austenitic grade with an average of $18 \% \mathrm{Cr} / 8 \% \mathrm{Ni}$ and the stabilized austenitic AISI321 grade. The object of this study is to evaluate the corrosion resistances of these three grades of stainless steels with a view to selecting the most stable of them as probable material of construction for the tar sand digester by the hot water process. 


\section{EXPERIMENTAL}

The stainless steels used in this work were obtained from a metal scrap market at Owode Onirin in Ikorodu, Lagos. Two of them are austenitic stainless steels of types AISI 304 and AISI 321 and a ferritic grade-AISI 430. The chemical compositions of these stainless steels are contained in Table 1. The lumps of Nigeria rich tar sand used for this work were obtained from a town called Agbabu in Ondo State around where Nigeria has a large deposit of tar sand. The energy dispersive X-ray analysis of the Nigerian rich tar sand used for investigation is as contained in Table 2 and Fig.6.

Table 1. Energy Dispersive X-ray Analysis of stainless steel samples. Atomic concentrations (atom \%)

\begin{tabular}{|l|l|l|l|l|l|l|l|l|}
\hline $\begin{array}{l}\text { Stainless } \\
\text { steel }\end{array}$ & $\mathrm{Cr}$ & $\mathrm{Ni}$ & $\mathrm{Ti}$ & $\mathrm{Mn}$ & $\mathrm{Al}$ & $\mathrm{Si}$ & $\mathrm{Fe}$ & $\mathrm{C}$ \\
\hline AISI 304 & 19.91 & 8.54 & - & - & 0.15 & 1.22 & 70.19 & 0.081 \\
\hline AISI 321 & 18.78 & 10.37 & 0.60 & 0.06 & - & 1.15 & 69.04 & 0.089 \\
\hline AISI 430 & 16.78 & - & - & - & - & - & 83.22 & 0.134 \\
\hline
\end{tabular}

Table 2. Energy Dispersive X-ray Analysis of the Nigerian rich tar sand investigated. Atomic concentrations (atom \%)

\begin{tabular}{|l|l|l|l|l|l|l|l|}
\hline $\mathrm{Na}$ & $\mathrm{Mg}$ & $\mathrm{Al}$ & $\mathrm{Si}$ & $\mathrm{P}$ & $\mathrm{S}$ & $\mathrm{Ca}$ & $\mathrm{Ti}$ \\
\hline 1.89 & 0.78 & 14.18 & 71.15 & 0.89 & 7.71 & 2.70 & 0.69 \\
\hline
\end{tabular}

The other materials used apart from the principal ones mentioned above and which were used either to simulate the tar sand digester condition or to assist in the sample preparation were all locally sourced.

Corrosion coupons were made from all the materials experimented in this work. Cutting and grinding of all samples were carefully handled. Holes were drilled in each of the sample with a $3 \mathrm{~mm}$ drill bit to facilitate suspension in the corrosion media. Each of the coupons, were ground to 600 grits starting with different emery grades of 240,320 or 400 grits. 600 grit is the recommended surface finish for corrosion exposure of coupons according to Fontana and Greene (1978). The grinding operation involved back and forth rubbing of specimens on the emery papers in directions roughly perpendicular to the scratches left by the preceding grinding paper.

After grinding, the metallographic samples were polished on the universal polishing machine. The polishing entailed the removal of fine scratches due to the finest grinding operation. This made the specimens' surfaces smooth and mirror-like. Polishing of the specimens in this work was carried out on two 6-inch rotating discs of a METASERV universal polisher. The two discs 
covered with new synthetic velvet cloths were impregnated with 5 and 0.3 microns diamond and alumina pastes respectively.

In order to remove the organic substances on the surfaces of the polished samples, the specimens were washed with non-bleaching scurrying powder, swabbed with water and then with acetone. This process removed all the grease, or dirt, present on the samples' surfaces, which would have been potential sources of errors and inaccuracies in the measurements of corrosion rates. The degreased surfaces were then air-dried with warm air from a laboratory drier. The samples were weighed using a sensitive chemical balance and recorded to the nearest $0.1 \mathrm{mg}$. The metallographic samples/coupons on the other hand, were not weighed but were etched subsequent to the microstructural study under an inverted metallurgical microscope.

\section{1 pH - measurement}

The $\mathrm{pH}$ measurement of the corrosive environment was taken throughout the period of the experiments at intervals of 48 hours. Prior to using the $\mathrm{pH}$ meter, the meter was standardized by first immersing the electrode in distilled water and then adjusting the meter to $\mathrm{pH}$ of 7 at room temperature. The distilled water was then wiped off the electrode with a tissue paper. Finally, the $\mathrm{pH}$ electrode was dipped in the medium to measure the $\mathrm{pH}$.

\subsection{Preparation of Corrosion Environment}

In order to be able to have a good assessment of the corrosion of the materials, the corrosion medium was prepared by simulating the tar sand digester conditions. A pulp of tar sand, sodium hydroxide and hot water were prepared to act as the corrosive environment. The Nigeria tar-rich sand, which came in lumps of black mass, was reduced to sizes less than $9.4 \mathrm{~mm}$ (i.e. $3 / 8$ inch) by crushing into smaller pieces (using hammer and chisel) prior to mixing with water (Miller and Misra, 1982). After sizing the tar-rich sand was dried in an oven set at $105^{\circ} \mathrm{C}$.

Aqueous solutions of $0.58 \mathrm{M}$ of sodium hydroxide was prepared and fed into the 4-litre plastic containers. Weighed quantity of the tar-rich sand was then fed into the sodium hydroxide solutions in the plastic containers followed by thorough mixing of the mixture with the aid of capillary rod. A steam bath filled with water was heated up to give a temperature of the corrosion media $90-95^{\circ} \mathrm{C}$. The pulp was left at this temperature range for various times depending on the experiment. Table 3 below provides a summary of the necessary conditions in the tar sand digester simulated as the corrosion media. 
Table 3. Experimental Conditions for hot water tar sand digestion

\begin{tabular}{|l|l|}
\hline Feed source & Rich tar sand deposit \\
\hline Wetting agent & $\mathrm{NaOH}$ \\
\hline Temperature & $95^{\circ} \mathrm{C}$ \\
\hline Percentage solids & $70 \mathrm{wt} . \%$ tar sands \\
\hline Digestion time & 15 minutes \\
\hline NaOH concentration & 0.58 mol/liter \\
\hline Feed size & Extruded to $-3 / 8$ inch \\
\hline Agitation & 750 r.p.m. \\
\hline
\end{tabular}

(After Sepulveda and Miller, 1978)

\section{RESULTS AND DISCUSSIONS}

Figure 1 depicts the corrosion behaviour of the three different stainless steels investigated in this study. From this figure the austenitic grades of stainless steels: AISI 321 SS and 304 SS show better corrosion resistance behaviour in the environment than the ferritic grade (AISI 430 SS) considered. Comparing the two austenitic grades, the stabilized AISI 321 SS showed better corrosion resistance than AISI 304 SS. This is probably because the 321 grade contains about $0.60 \% \mathrm{Ti}$ in addition to increased nickel content of the steel (10.37Ni) in comparison with the AISI304 grade (that contains only $8.54 \mathrm{Ni}$ ).

The micrographs in Figs. 2 to 5 of the corroded stainless steel samples after twenty days of immersion showed a greater tendency to pitting or crevice corrosion by the 430 grades than the austenitic grades. The micrograph of Fig. 2 is of the corroded surface of the AISI 430 stainless steel. The micrograph shows features that resemble wide spread of pits all over the surface. Fig. 3 is a better resolution of the corroded surface of the AISI 430 SS. It shows that some of these pits because of their depths probably started as crevice corrosion under a tar sand deposit that stuck to the surface of the samples. It is also being suspected that some of the pits probably arose from the pitting corrosion around inclusions in the matrix of the stainless steel and some from the presence of some elements in the Nigerian tar rich sand as will be explained later. Figs. 4 and 5 show the corroded surfaces of the 304 and the 321 stainless steels respectively. In both of them the tendency for pitting and crevice corrosions is remote. In general, our observations also showed partial removal of chromia film $\left(\mathrm{Cr}_{2} \mathrm{O}_{3}\right)$ on the surface of the austenitic grades. According to the literature (Oluwole et al, 1980 and Ukwuoma and Ademodi, 1999) some of the 
Nigerian tar sands contain chloride (although in very small amount), the activities of the chlorine ions at the crevices must have been the reduction and subsequent dissolution of chromia films on the surfaces of the steel.

From the results of the analysis of some Nigerian tar sand bitumen by Oluwole et al(1980) and as evident for some of the elements in Fig. 6 it is clear that the tar sand environment contains in traces the following elements calcium, iron, potassium, magnesium, sodium, nickel and vanadium. All these elements apart from nickel and vanadium are more base (i.e. more active) than iron/steel because of their positions in the electrochemical series or the galvanic series. The quantities of vanadium and the vanadium to nickel ratio quoted in the analysis show that these elements are present in significant amount. In a corrosion environment like that of tar sand bitumen it is suspected that numerous galvanic cells would have been set up between iron of steel and the vanadium and nickel metals present in tar sand. And the iron/steel because of its position in the galvanic series would be anodic while trace metals ( $\mathrm{V}$ and $\mathrm{Ni}$ ) will be cathodic. The corrosion reactions between the three elements in the tar sand environment can be therefore be written as

$$
\begin{aligned}
& \text { Anodic reaction: } \mathrm{Fe}=\mathrm{Fe}^{2+}+2 \mathrm{e}^{-} \\
& \text {Cathodic reactions }\left\{\begin{array}{l}
V^{+}+e^{-}=V \\
\mathrm{Ni}^{2+}+2 e^{-}=\mathrm{Ni}
\end{array} \quad\right. \text { metal atom depositions }
\end{aligned}
$$

That is, the metal ion deposition is a possible cathodic reaction in tar sand corrosion reactions. As a result of the localization of these reactions on the surface of the steels we have some pockets of pits on the corroded surface as evidenced in the SEM micrographs of Figs. 2 and 3 due to the ferritic AISI430 stainless steel.

The other trace elements because of their electrode potentials with respect to that of iron in steel are expected to put up sacrificial cathodic protection of the steel surface according to the reactions

Anode: $\quad \mathrm{Ca}=\mathrm{Ca}^{2+}+2 \mathrm{e}^{-}$

$$
\begin{aligned}
& \mathrm{K}=\mathrm{K}^{+}+\mathrm{e}^{-} \\
& \mathrm{Mg}=\mathrm{Mg}^{2+}+2 \mathrm{e}^{-} \\
& \mathrm{Na}=\mathrm{Na}^{+}+\mathrm{e}^{-}
\end{aligned}
$$

and the cathode reactions in the vicinity of the above are suspected to also include:

$1 / 2 \mathrm{O}_{2}+\mathrm{H}_{2} \mathrm{O}+2 \mathrm{e}^{-}=2 \mathrm{OH}^{-}$(due to the presence of dissolved $\mathrm{O}_{2}$ ), and

$2 \mathrm{H}^{+}+\mathrm{e}^{-}=\mathrm{H}_{2}$ (g) (due to the presence of excess $\mathrm{H}^{+}$ions produced by the dissociation of the organic acids in the medium). 


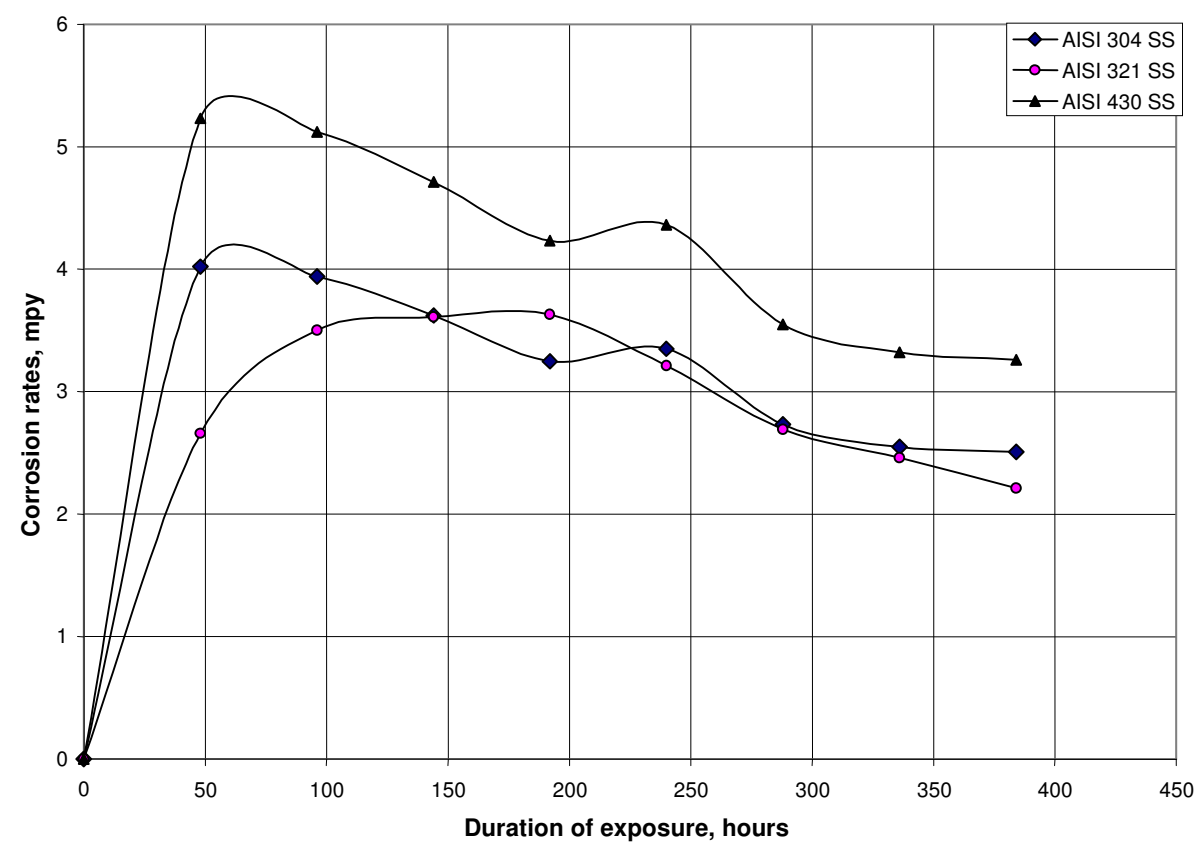

Fig. 1. Corrosion of types AISI 430, AISI 304 and AISI 321 stainless steels in a tar sand digester

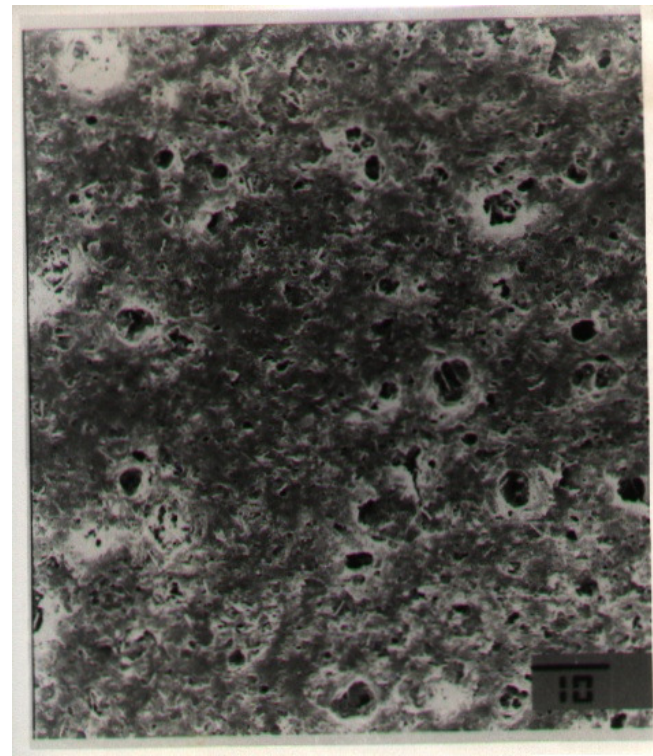

Fig.2 Scanning electron micrograph of a corroded AISI 430 SS after 20 days of exposure $\mathrm{x} 1000$

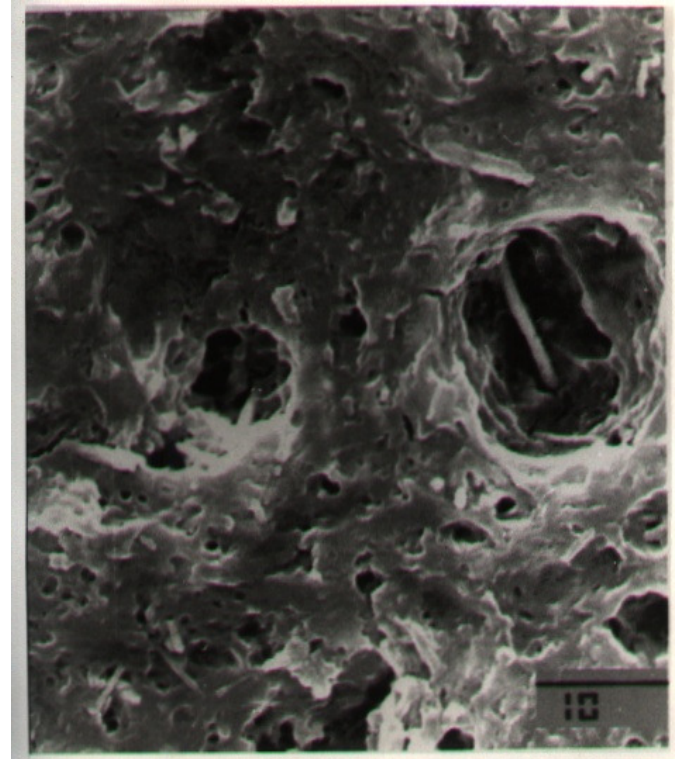

Fig.3. Scanning electron micrograph of a corroded AISI 430 SS after 20 days of exposure $\mathrm{x} 5000$ 


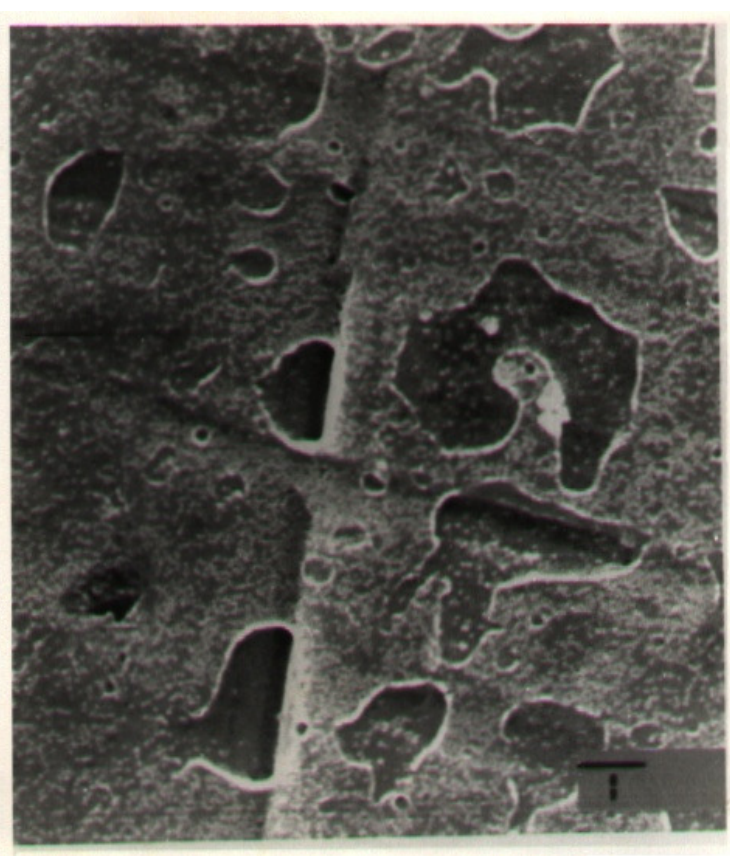

Fig.4. Scanning electron micrograph of a corroded AISI 304 SS after 20 days of exposure $\mathrm{x} 1000$

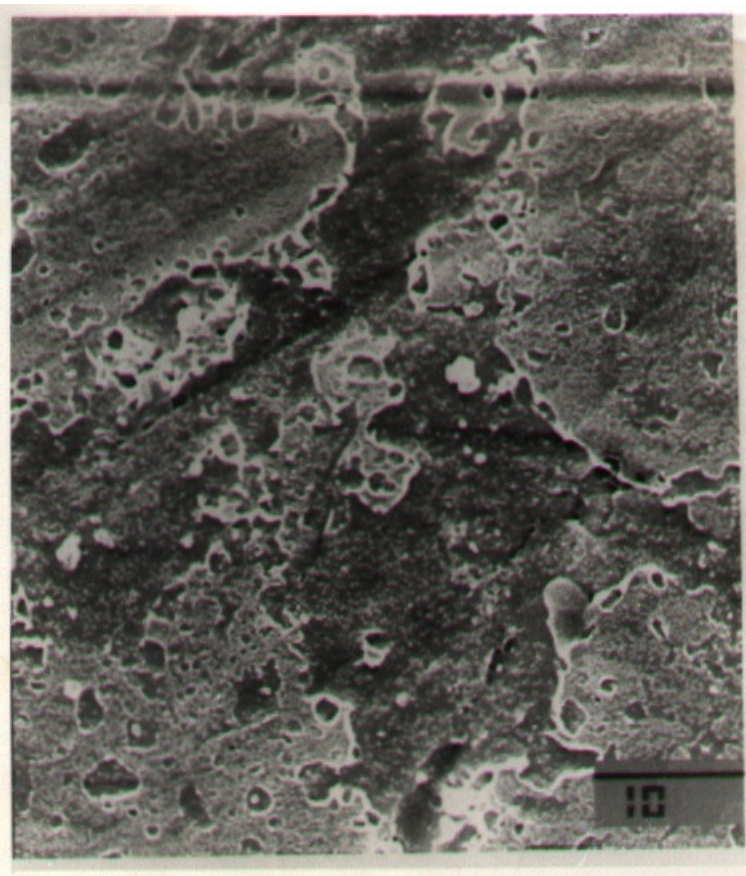

Fig.5. Scanning electron micrograph of a corroded AISI $321 \mathrm{SS}$ after 20 days of exposure x 5000

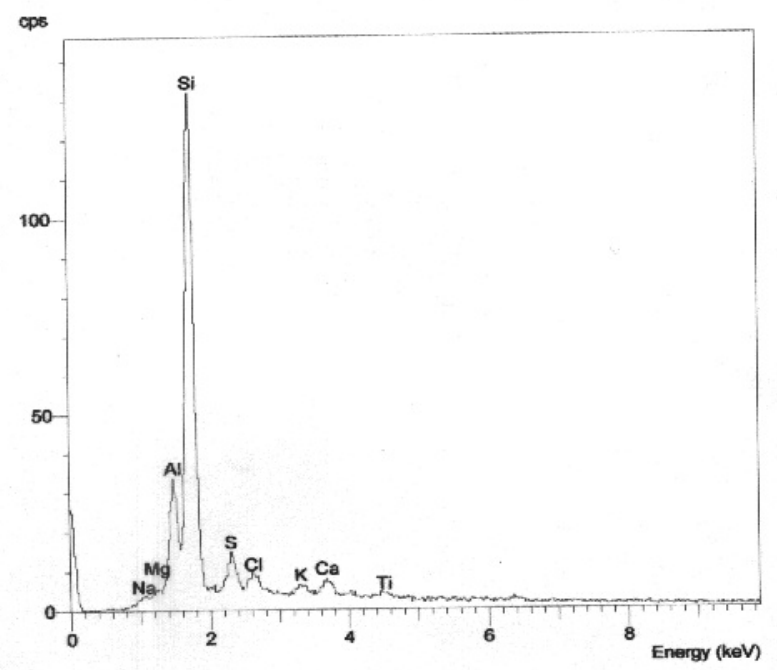

Fig.6 Energy Dispersive X-ray analysis of Nigerian rich tar sand. 


\section{CONCLUSIONS}

From the results and observations in this study it can be concluded that

i. The ferritic stainless steels are susceptible to pitting and crevice forms of corrosion in the tar sand digester medium and that

ii. the Austenitic stainless steels(AISI 304 and 321) are more resistant to the corrosion activities of the tar sand digester environment than the ferritic stainless steel-AISI430.

\section{REFERENCES}

Collins, A.G. (1975) Geochemistry of the oil field waters, Elsevier Scientific Publishing Company, New York, pp194.

Fontana, C.M. and Greene, N.D. (1983) Corrosion Engineering, $2^{\text {nd }}$ edition, McGraw-Hill International Book Company

Koser, H.J.K. (1980) corrosion of metals in carbon tetrachloride containing solvent, Analyst pp123

Miller, J.D. and Misra, M. (1982) Hot water process development for Utah tar sands, Fuel Processing Technology, Vol.6, pp 27-59.

Oluwole, A.F., Kehinde,L.O. and Adeogoke, A.A. (1980) Chemical composition of tar sand, Journal of Centre for Energy Research and Development, Obafemi Awolowo University, Ile-Ife and Alberta. Canada.

Peter, D.C., James, B.H. and David, T.J. (1984) Some chemistry of organosulphur compound types occurring in heavy oil sands. High temperature hydrolysis and thermolysis of tetrahydrothiopene in relation to steam stimulation process, Fuels, Vol. 62 pp959-962.

Sepulveda, J.F. and Miller, J.D. (1978) Extraction of bitumen from Utah tar sands by hot water digestion flotation technique, mining Engineering Vol.30 No. 9 pp1311.

Ukwuoma, O. and Ademodi, B. (1999) The study of composition of Nigerian tar sand bitumen, Petroleum Science and Technology, Vol. 17, (1-20), pp 57-65.

Umoru, L.E. (2001) A study of corrosion of materials in a tar sand digester, Ph.D. Thesis, Obafemi Awolowo University, Ile-Ife. Nigeria. 